\title{
Quantitative assessment of BIGV and structural response based on velocity and frequency around an opencast mine
}

\author{
Anand Kumar*, Pusker Singh, Sanjay Kumar Sharma, Nawal Kishore and \\ C. S. Singh \\ Department of Mining Engineering, Indian Institute of Technology (BHU), Varanasi 221005 , India
}

\begin{abstract}
Blast-induced ground vibration (BIGV) velocities and frequencies are of major concern due to their adverse effects and damage to structures. Therefore, it becomes essential to assess the velocities and frequencies induced by blasting in terms of quantitative and qualitative assessment to overcome the problems. There is a need for scientific studies using devices like triaxial geophone associated with a seismograph to measure the peak particle velocity (PPV) and dominant frequency which cause damage to domestic or residential structures near an opencast mine. Each mine has specific geo-mining conditions, and scientific studies provide appropriate results. In total, 32 number of blasting data sets were recorded at every $50 \mathrm{~m}$ from the blast site to the last observation point near the village. Ground vibration associated damage criteria is defined in terms of the PPV at different frequency levels and the strength of the structures under study. The permissible limits of BIGV has been provided by the Directorate General of Mines Safety, Dhanbad, India. The permissible PPV values of the BIGV in India is 2, 5, 10 for the historical and sensitive structures, 5, 10, 15 for domestic houses and 10, 20, 25 for industrial buildings at $<8,8-25$ and $>25 \mathrm{~Hz}$ dominant excitation frequencies respectively. The recorded dataset has been proposed through standard models. The velocity amplitude versus frequency gives a reliable relationship about damage criteria of structures. The structures were analysed vis-à-vis PPV and dominant frequency to correlate the damage possibility. The present study carried out in a mega opencast project provides the basic knowledge to assess the safe distance from blasting site for specific charge of explosive, waves which are responsible for more damage to nearby structures and to determine the correlation coefficient between measured and predicted PPV values.
\end{abstract}

Keywords: Frequency, ground vibration, opencast mine, peak particle velocity, structural response.

THE evaluation, monitoring and control of blast-induced ground vibration (BIGV) have become essential for people and structures near a mine. The blast-induced

*For correspondence. (e-mail: anandkumar.rs.min14@itbhu.ac.in) seismic wave energy (BISWE) is an uncontrolled parameter which propagates into the medium by its own character. A small portion of energy is utilized for removal of overburden and broken rock mass. A large portion of seismic energy propagates and covers some distance around the blasting patch. The radius of amplitude of seismic wave decreases with increasing distance. The seismic wave propagates with high energy into subsurface medium causing ground vibration or shaking. Therefore, BIGV causes damage, hazard risk, financial problems and discomfort for people and structures near the mines. Sometimes vibration level exceeds the threshold and becomes more hazardous for people and structures around a mine. Upon damage to structures and injury to people, mines are approached for the compensation of losses ${ }^{1}$. The frequency and peak particle velocity (PPV) are the most essential parameters to assess BIGV and seismic hazard relationship ${ }^{1-4}$. The component velocities - radial, vertical and transverse get registered on a triaxial geophone and maximum among them is called the resultant PPV value. PPV is affected by parameters like distance, physical properties of rock mass, geological condition, density and amount of explosive, etc. It attenuates with increasing amplitude from the source ${ }^{5}$. The insecurity of the people residing in BIGV influence zone is due to their ignorance of the permissible limit of the PPV for the structures. Therefore, the ground vibrations and noise associated with blasting, even within acceptable limits, cause panic among them ${ }^{6}$. People living nearby notice and react to vibration at much lower level than approved permissible level by legislation which does not cause the damage $^{7-9}$. The frequency plays a key role to determine ground vibration intensity of seismic waves. It is defined as the number of shocks or oscillations per second $(\mathrm{Hz})$; the relationship among seismic wave velocity $(V)$, dominant frequency $(f)$ and wavelength $(\varphi)$ is as given in eq. (1)

$$
V=f * \varphi \text {. }
$$

The structures vibrate at their natural frequencies which is normally small. Therefore at lower frequencies, damages are expected at lower PPV. The natural frequency of the different structures varies from 4 to $18 \mathrm{~Hz}$ (ref. 10). 


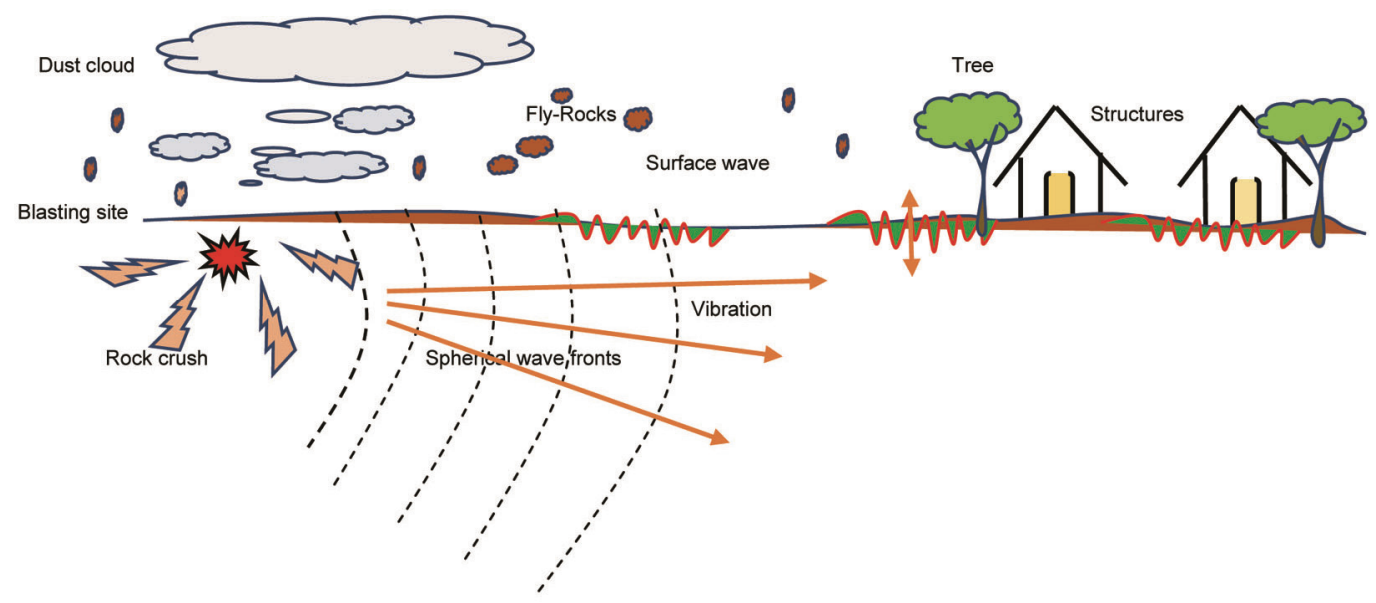

Figure 1. Impact of blasting on surrounding environment and structure.

Therefore, the researchers attempt to measure PPV at different locations and at different frequency levels to establish the relationship of the level of intensity of the BIGV (velocity, frequency, displacement and acceleration) with blasting at any site ${ }^{11-17}$. This is significant as it decides the potential of damage to structures and human discomfort, within the zone of influence. Finally, damages correlate with the PPV of $\mathrm{BIGV}^{18}$. The basic prediction model eq. (2) proposed by USBM

$$
\mathrm{PPV}=k(\mathrm{SD})^{-b},
$$

where scale distance (SD) is a function of measuring distance $(D)$ and maximum charge per delay $(Q)$, and $k$ and $b$ are the site-specific constants. Scientists have proposed modified ground vibration prediction model equations. Blasting is a matter of serious concern for the environment around a mine and for people from nearby villages. It consists of ground vibration energy, air overpressure, fly rock, dust cloud, noise, etc. (Figure 1). The community requires safety, minimization of hazardous risk, health insurance and compensation for their losses ${ }^{10,12,19-21}$.

The main objective of this study was to predict the intensity of ground vibration caused by blasting at an opencast coal mine of Chhattisgarh, India and mitigate or minimize its negative effects on residential structures within $550 \mathrm{~m}$ by determining a safe charge weight per delay.

Ground vibration data were acquired from eight different blasts carried out in an opencast mine using four Nomis seismographs. The distance between blast site and observation point was measured using GPS. The amount of explosive and maximum charge per delay were noted for further analysis. A regression analysis was subsequently done on the recorded datasets to derive a sitespecific attenuation equation which relates the intensity of ground vibration to scaled distance. This attenuation equation helps predict PPV for a particular site. A com- parison was made between measured and predicted PPV values to verify the accuracy of the attenuation.

The field survey and the data collection had been carried out, during the blasting operations for measuring the real time intensity of the ground vibrations, near the structures that had reported BIGV associated problems. Blast-induced ground vibration data were acquired by recording 32 datasets using four seismographs. Nomis Super Graphics Software along with regression analysis software were used for the post acquisition data analysis.

\section{Study area and geological overview}

The study was conducted at 'mine A' (lat. $22^{\circ} 19^{\prime} 14.988^{\prime \prime} \mathrm{N}$ and long. 82 $31^{\prime} 30.67^{\prime \prime} \mathrm{E}$ ) (Figure 2). Granite, dolerite, bauxite, fireclay and limestone deposits are also found in this area. The overburden rock mass is of medium to coarse grained sandstone, shale, shaly sandstone and mostly weathered sandstone. The mine has semi-consolidated sediments and bituminous coal of Gondwana age $\mathrm{e}^{22,23}$.

\section{Blasting vibration standard and safe levels to prevent damage}

Various countries have established their own vibration standards on the basis of experimental investigations in their mines to demonstrate the impact of BIGV on the surrounding environment and the structures. Vibration standard limits depend only on the basic parameters, viz. frequency and PPV. All structures have their own natural frequency. Researchers have set the PPV values of different structures at their natural frequencies and proposed a model for blasting damage criteria. The United States Bureau of Mines published the RI 8507 model for blasting damage criteria which sets the PPV limits according to the frequency of a structure ${ }^{8}$ (Table 1). Tables 2 and 3 show the German Standard DIN4150 (1986) ${ }^{24}$ and the 


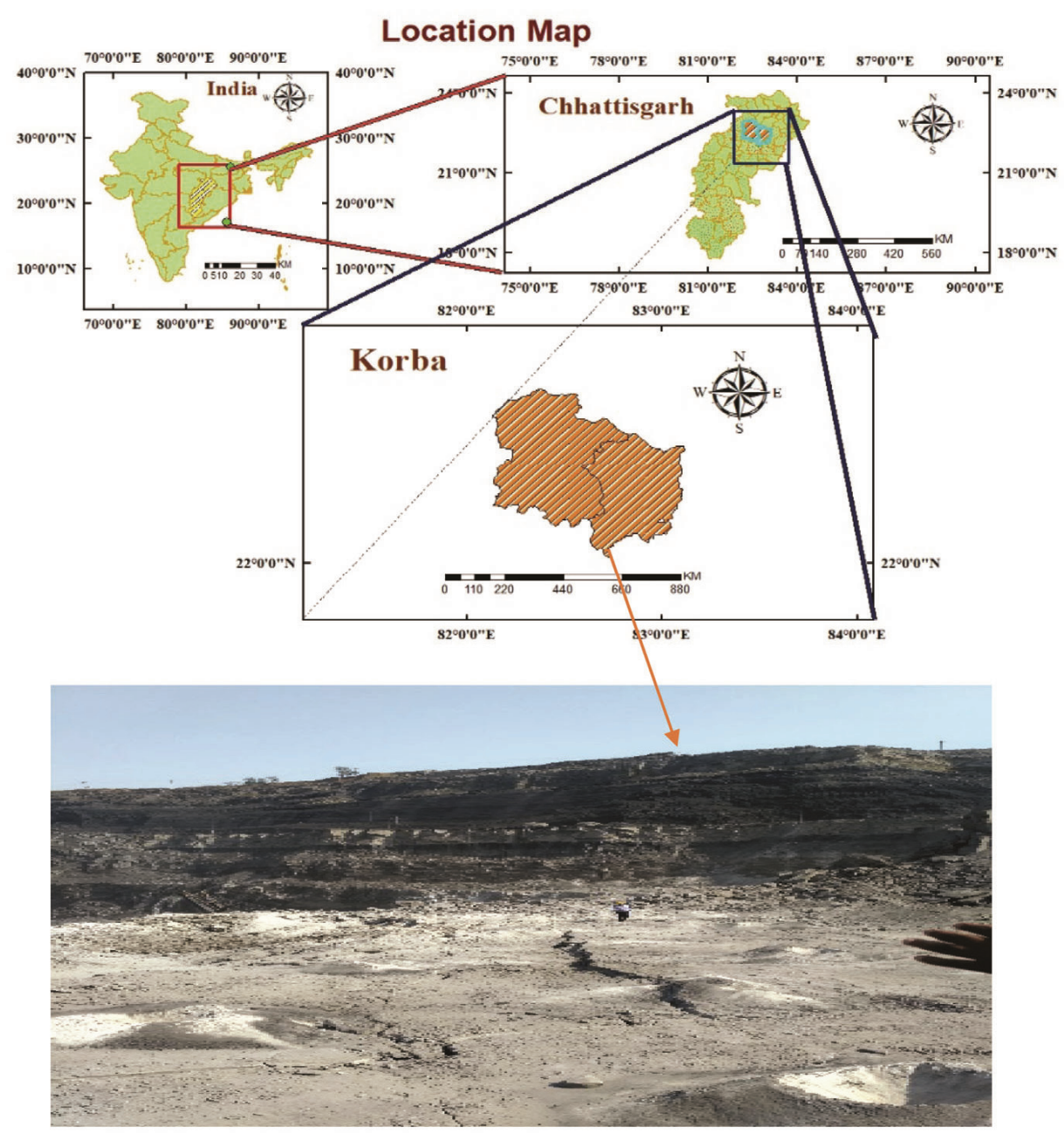

Figure 2. Location map and mine site.

Table 1. USA standard proposed the permissible limit of structures, after Siskind et al. ${ }^{15}$

\begin{tabular}{lcc}
\hline & \multicolumn{2}{c}{ Peak particle velocity $(\mathrm{PPV} ; \mathrm{mm} / \mathrm{s})$} \\
\cline { 2 - 3 } Type of structure & Frequency $(<40 \mathrm{~Hz})$ & Frequency $(>40 \mathrm{~Hz})$ \\
\hline Modern homes, dry wall interior & 18.75 & 50 \\
Older homes, plaster on wood lath construction & 12.50 & 50 \\
\hline
\end{tabular}

Australian Standard 2006 (AS 2187.2) ${ }^{20}$ respectively. The PPVs are measured from the blast site to the last observation point (near village structures). The minimum PPV $5 \mathrm{~mm} / \mathrm{s}$ at frequency $(<8 \mathrm{~Hz})$ for domestic houses, proposed by the Indian Standard (DGMS circular 7 of 1997) $(\text { Table } 4)^{25}$.

\section{Materials and methods}

\section{Blast design geometry}

In the field, a simple procedure is applied due to irregular or complex nature of the mine. First, a survey line is made from the blasting site at the mine to the last obser- vation point near the structures (Hardi Bazar) (1.40$1.50 \mathrm{~km}$ long). Blast design parameters and materials range such as hole depth (3.5-20 m), hole diameter (160$381 \mathrm{~mm})$, burden $(3.5-8 \mathrm{~m})$, stemming equal to burden, spacing (3.0-8.5 m), charge per hole $(19.1-560 \mathrm{~kg})$, bench height $(3.0-20 \mathrm{~m})$, booster per hole (100-1200 g), velocity of detonation $(3500-4500 \mathrm{~m} / \mathrm{s})$ and staggered pattern have been used. Figure 3 provides blast design and drill-hole description. Ammonium nitrate and fuel oil (ANFO), i.e. a mixture of (94\%-95\%) ammonium nitrate and $(5 \%-6 \%)$ fuel oil has been used. The non-electric Nonel delay operators as 17 and $42 \mathrm{~ms}$ are used in line and cross line respectively, along with DTH delay of 200-250 ms (ref. 26). 
Table 2. German standard proposed the permissible level of structures after German DIN $4150(1986)^{24}$

\begin{tabular}{|c|c|c|c|}
\hline \multirow[b]{2}{*}{ Type of structures } & \multicolumn{3}{|c|}{$\mathrm{PPV}(\mathrm{mm} / \mathrm{s})$ at foundation } \\
\hline & $<10 \mathrm{~Hz}$ & $10-50 \mathrm{~Hz}$ & $50-100 \mathrm{~Hz}$ \\
\hline Offices and industrial premises & 20 & $20-40$ & $40-50$ \\
\hline Domestic houses and similar constructions & 5 & $5-15$ & $15-20$ \\
\hline Buildings that do not come under the above because of their sensitivity to vibration & 3 & $3-8$ & $8-10$ \\
\hline
\end{tabular}

Table 3. Permissible level of structures as proposed by the Australian Standard 2006 (AS 2187.2) ${ }^{20}$

\begin{tabular}{lc}
\hline Type of structure & \\
\hline $\begin{array}{l}\text { Historical building and monuments and building of special value } \\
\text { Houses and low-rise residential buildings, commercial buildings } \\
\text { not included below }\end{array}$ & $0.2 \mathrm{~mm}$ displacement for frequencies less than $15 \mathrm{~Hz}$ \\
$\begin{array}{l}\text { Commercial buildings and industrial buildings or structures of } \\
\text { reinforced concrete or steel construction }\end{array}$ & $0.2 \mathrm{~mm}$ maximum displacement corresponding to $12.5 \mathrm{~mm} / \mathrm{s}$ PPV at \\
\hline
\end{tabular}

Table 4. Permissible level of structures as proposed by the Indian Standard (DGMS circular 7 of 1997) $)^{25}$

\begin{tabular}{|c|c|c|c|}
\hline & \multicolumn{3}{|c|}{ Dominant excitation frequency $(\mathrm{Hz})$} \\
\hline & $<8$ & $8-25$ & $>25$ \\
\hline \multicolumn{4}{|l|}{ (A) Buildings/structures not belonging to the owner } \\
\hline 1. Domestic houses/structures (kuchcha, brick and cement) & 5 & 10 & 15 \\
\hline 2. Industrial buildings & 10 & 20 & 25 \\
\hline 3. Objects of historical importance and sensitive structures & 2 & 5 & 10 \\
\hline \multicolumn{4}{|l|}{ (B) Buildings belonging to the owner with limited life span } \\
\hline 1. Domestic houses/structures & 10 & 15 & 25 \\
\hline 2. Industrial buildings & 15 & 25 & 50 \\
\hline
\end{tabular}

\section{Instrument and datasets}

The ground vibrations were monitored using a seismograph which contains a triaxial geophone. Four seismographs were stacked in a group and defined as one channel at the mentioned interval. The seismographs were located at every $100 \mathrm{~m}$ interval, but data were monitored at every $50 \mathrm{~m}$ interval, viz. $50,100,150,200, \ldots$, $1350,1400 \mathrm{~m}$. The seismographs (4-channel) were moved from the blast site to the last observation point (near village structures) on the imaginary drawn line. A total number of 32 datasets have been measured in different forms like PPV, frequency and their components radial, transverse, vertical, etc. in some days (Table 5).

\section{Ground vibration prediction}

The distance and maximum charge per delay are the most essential parameters to determine the predicted PPV, but this is not sufficient because of heterogeneity of rock mass. The characteristics of rock mass change from one place to another and act as catalysts also, therefore, the vibration energy is transmitted, refracted and reflected from the rock mass. Therefore, PPV and frequency are signi- ficantly affected. The site-specific characteristic constants $(k, b)$ are necessary to establish new relationship for particular mine site. Linear regression analysis is compulsory for determination of the site-specific constants ( $k=478.63, b=-1.5)$, because it establishes the relationship between dependent (PPV) and independent (SD) variables. It gives the equation of a straight line (eq. (3)). The intercept and slope of the line are defined as sitespecific constants, i.e. logarithmic plotting between measured PPV $(\mathrm{mm} / \mathrm{s})$ and SD $\left(\mathrm{m} / \mathrm{kg}^{0.5}\right)$ that is a function of $D(\mathrm{~m})$ and $Q(\mathrm{~kg})$, as mentioned in eq. (2). The sitespecific constants are not valid for other sites due to heterogeneity of rock mass. To determine the site-specific constants, at least 30 datasets are required for good performance of regression analysis to establish the attenuation equation, according to the Office of Surface Mining Reclamation and Enforcement (OSMRE), United States. Vector sum is defined as the square root of sum of squares of component velocities (radial $l$, transverse $t$ and vertical v), i.e. PPV that can be obtained using manual calculation as shown in eq. (4).

$$
\log \mathrm{PPV}=2.679-1.5(\log D-0.5 \log Q) .
$$

Vector sum $=\sqrt{l^{2}+t^{2}+v^{2}}$. 

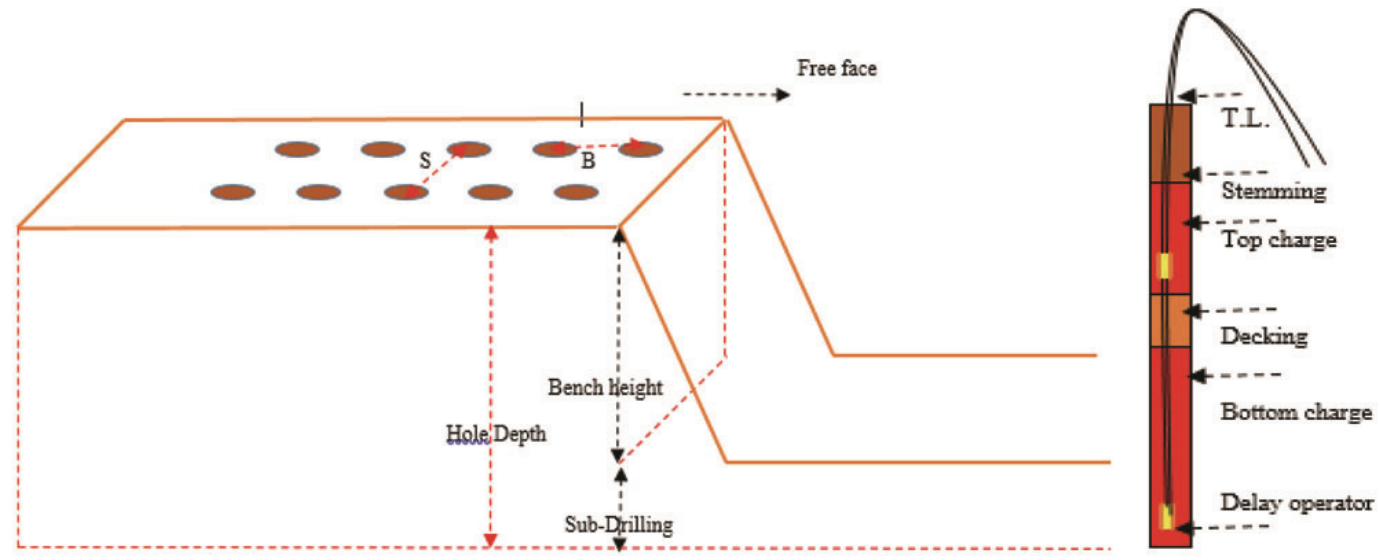

Figure 3. Blast design geometry and blast hole design ${ }^{27}$.

Table 5. The measured and predicted PPV and frequency

\begin{tabular}{|c|c|c|c|c|c|c|c|c|c|c|c|}
\hline \multirow{2}{*}{$\begin{array}{l}\text { Distance } \\
(\mathrm{m})\end{array}$} & \multirow{2}{*}{$\begin{array}{l}\text { Maximum } \\
\text { charge per } \\
\text { delay }(\mathrm{kg})\end{array}$} & \multirow{2}{*}{$\begin{array}{c}\text { Scale } \\
\text { distance } \\
\left(\mathrm{m} / \mathrm{kg}^{0.5}\right)\end{array}$} & \multicolumn{5}{|c|}{$\mathrm{PPV}(\mathrm{mm} / \mathrm{s})$} & \multicolumn{4}{|c|}{ Frequency $(\mathrm{Hz})$} \\
\hline & & & Radial & Transverse & Vertical & Measured & Predicted & Radial & Transverse & Vertical & Measured \\
\hline 100 & 85.76 & 10.798 & 9.525 & 8.255 & 6.985 & 9.525 & 13.488 & 2.6 & 2.7 & 6.6 & 2.6 \\
\hline 200 & 85.76 & 21.596 & 6.096 & 5.842 & 4.064 & 6.096 & 4.769 & 3.2 & 1.9 & 2.2 & 3.2 \\
\hline 300 & 85.76 & 32.395 & 3.810 & 3.429 & 1.270 & 3.81 & 2.596 & 6.1 & 5.6 & 6.9 & 6.1 \\
\hline 50 & 118.7 & 4.589 & 18.235 & 19.609 & 17.563 & 19.609 & 48.687 & 25.2 & 23.5 & 19.1 & 25.2 \\
\hline 150 & 118.7 & 13.767 & 11.049 & 10.795 & 6.096 & 11.049 & 9.369 & 11.6 & 10.4 & 18.2 & 11.6 \\
\hline 250 & 118.7 & 22.946 & 4.191 & 3.429 & 1.143 & 4.191 & 4.354 & 6 & 5.1 & 6.2 & 6 \\
\hline 350 & 371 & 18.171 & 5.207 & 5.334 & 6.487 & 5.334 & 6.179 & 5 & 3.8 & 4 & 3.8 \\
\hline 450 & 371 & 23.362 & 3.124 & 2.894 & 4.081 & 4.081 & 4.238 & 2.3 & 2.5 & 2.8 & 2.8 \\
\hline 550 & 371 & 28.554 & 3.683 & 2.286 & 1.905 & 3.683 & 3.137 & 5.3 & 10 & 10.8 & 5.3 \\
\hline 650 & 371 & 33.746 & 2.413 & 2.413 & 1.651 & 2.413 & 2.442 & 4.6 & 3.3 & 5.3 & 4.6 \\
\hline 400 & 324.1 & 22.218 & 5.842 & 6.604 & 4.826 & 6.604 & 4.570 & 12.1 & 8 & 16.5 & 8 \\
\hline 500 & 324.1 & 27.773 & 4.064 & 2.413 & 0.762 & 4.064 & 3.270 & 4.3 & 4.5 & 32 & 4.3 \\
\hline 600 & 324.1 & 33.328 & 2.159 & 2.540 & 0.381 & 2.54 & 2.487 & 2.4 & 2.8 & 0 & 2.8 \\
\hline 700 & 324.1 & 38.882 & 1.778 & 1.143 & 0.254 & 1.778 & 1.974 & 0.8 & 1.6 & 0 & 0.8 \\
\hline 325 & 102.8 & 32.054 & 3.429 & 3.429 & 1.143 & 3.429 & 2.637 & 6.3 & 3.9 & 8.6 & 3.9 \\
\hline 525 & 102.8 & 51.780 & 0.889 & 0.508 & 0.254 & 0.889 & 1.284 & 1.1 & 1.4 & 1.2 & 1.2 \\
\hline 725 & 102.8 & 71.505 & 0.153 & 0.197 & 0.175 & 0.197 & 0.791 & 1.2 & 1.4 & 1.3 & 1.4 \\
\hline 650 & 475 & 29.824 & 4.826 & 3.429 & 2.286 & 4.826 & 2.938 & 5.2 & 7.6 & 6.2 & 5.2 \\
\hline 750 & 475 & 34.412 & 1.143 & 3.556 & 0.508 & 3.556 & 2.370 & 1.6 & 1.8 & 1.5 & 1.8 \\
\hline 1150 & 475 & 52.765 & 1.905 & 1.651 & 1.270 & 1.905 & 1.248 & 6.2 & 7.4 & 17 & 6.2 \\
\hline 1250 & 475 & 57.353 & 1.016 & 0.762 & 0.762 & 1.016 & 1.102 & 5.3 & 4.7 & 4.7 & 5.3 \\
\hline 800 & 221.84 & 53.711 & 1.270 & 1.143 & 1.016 & 1.27 & 1.216 & 3.5 & 2.9 & 4.3 & 3.5 \\
\hline 900 & 221.84 & 60.425 & 0.635 & 0.381 & 0.762 & 0.762 & 1.019 & 2.6 & 1.6 & 3.9 & 3.9 \\
\hline 1000 & 221.84 & 67.139 & 0.335 & 0.236 & 0.248 & 0.335 & 0.870 & 1.4 & 1.05 & 1.52 & 1.4 \\
\hline 850 & 470 & 39.207 & 4.191 & 4.318 & 2.159 & 4.318 & 1.949 & 2.2 & 1.6 & 0.8 & 2.2 \\
\hline 950 & 470 & 43.820 & 3.048 & 2.540 & 1.397 & 3.048 & 1.650 & 6.3 & 6.1 & 8.4 & 6.1 \\
\hline 1100 & 470 & 50.739 & 2.032 & 2.159 & 1.270 & 2.159 & 1.324 & 4.4 & 3.9 & 15.5 & 3.9 \\
\hline 1200 & 470 & 55.351 & 1.524 & 1.524 & 0.254 & 1.524 & 1.162 & 6.3 & 7.1 & 0 & 7.1 \\
\hline 1050 & 390 & 53.168 & 1.143 & 1.143 & 0.889 & 1.143 & 1.234 & 7.3 & 6.1 & 6.3 & 7.3 \\
\hline 1300 & 390 & 65.828 & 0.889 & 0.889 & 0.254 & 0.889 & 0.896 & 8.3 & 5.1 & 0 & 5.1 \\
\hline 1350 & 390 & 68.359 & 0.635 & 0.635 & 0.254 & 0.635 & 0.846 & 1.4 & 2.3 & 1.9 & 2.3 \\
\hline 1400 & 390 & 70.891 & 0.421 & 0.547 & 0.364 & 0.547 & 0.801 & 1.2 & 1.46 & 1.14 & 1.46 \\
\hline
\end{tabular}

\section{Results and discussion}

In the present study, the main focus was on the dwelling structures like kuchha and pukka (concrete) houses. The Indian standard proposed permissible limits of less than or equal to $5 \mathrm{~mm} / \mathrm{s}$ of peak particle velocity for the domestic structures at frequencies less than $8 \mathrm{~Hz}$. If BIGV is within this limit then the domestic structures are safe.

The Indian standard proposed permissible limits of less than or equal to $5 \mathrm{~mm} / \mathrm{s}$ of peak particle velocity for the domestic structures at frequencies less than $8 \mathrm{~Hz}$. If BIGV is within this limit then the domestic structures are safe. It 


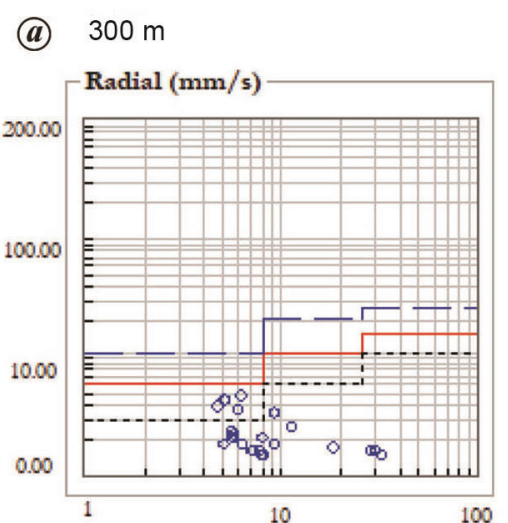

(b) $350 \mathrm{~m}$

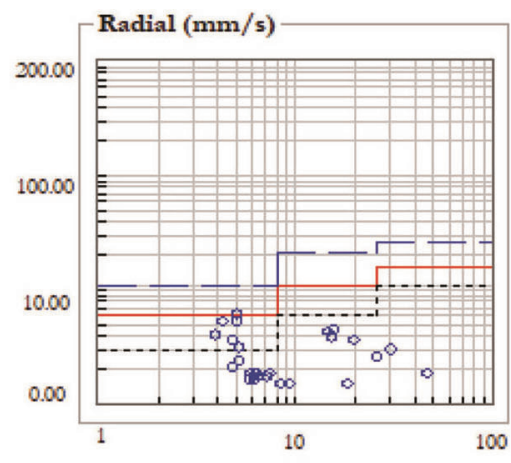

(c) $500 \mathrm{~m}$

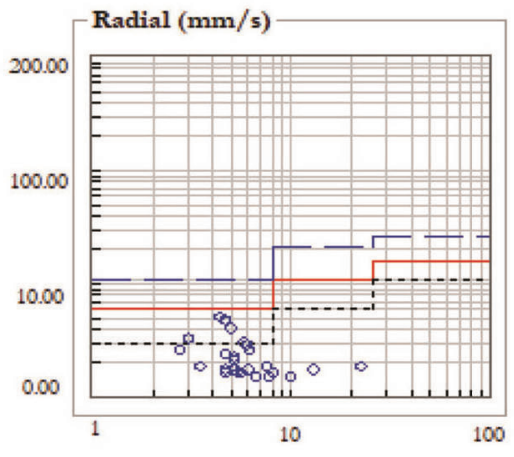

(d) $550 \mathrm{~m}$

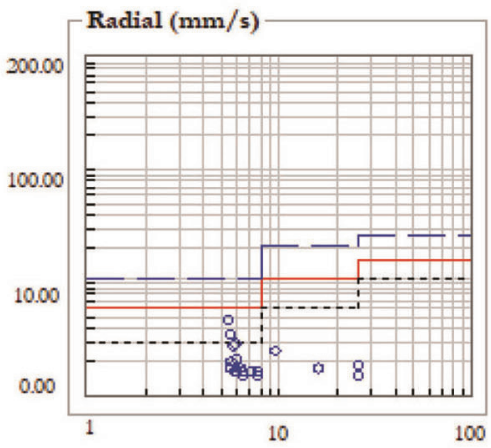

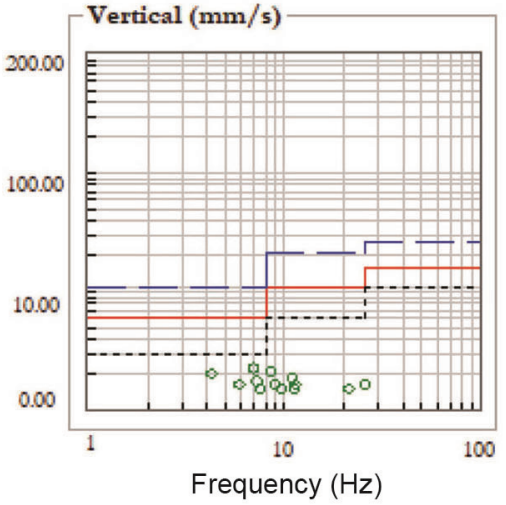
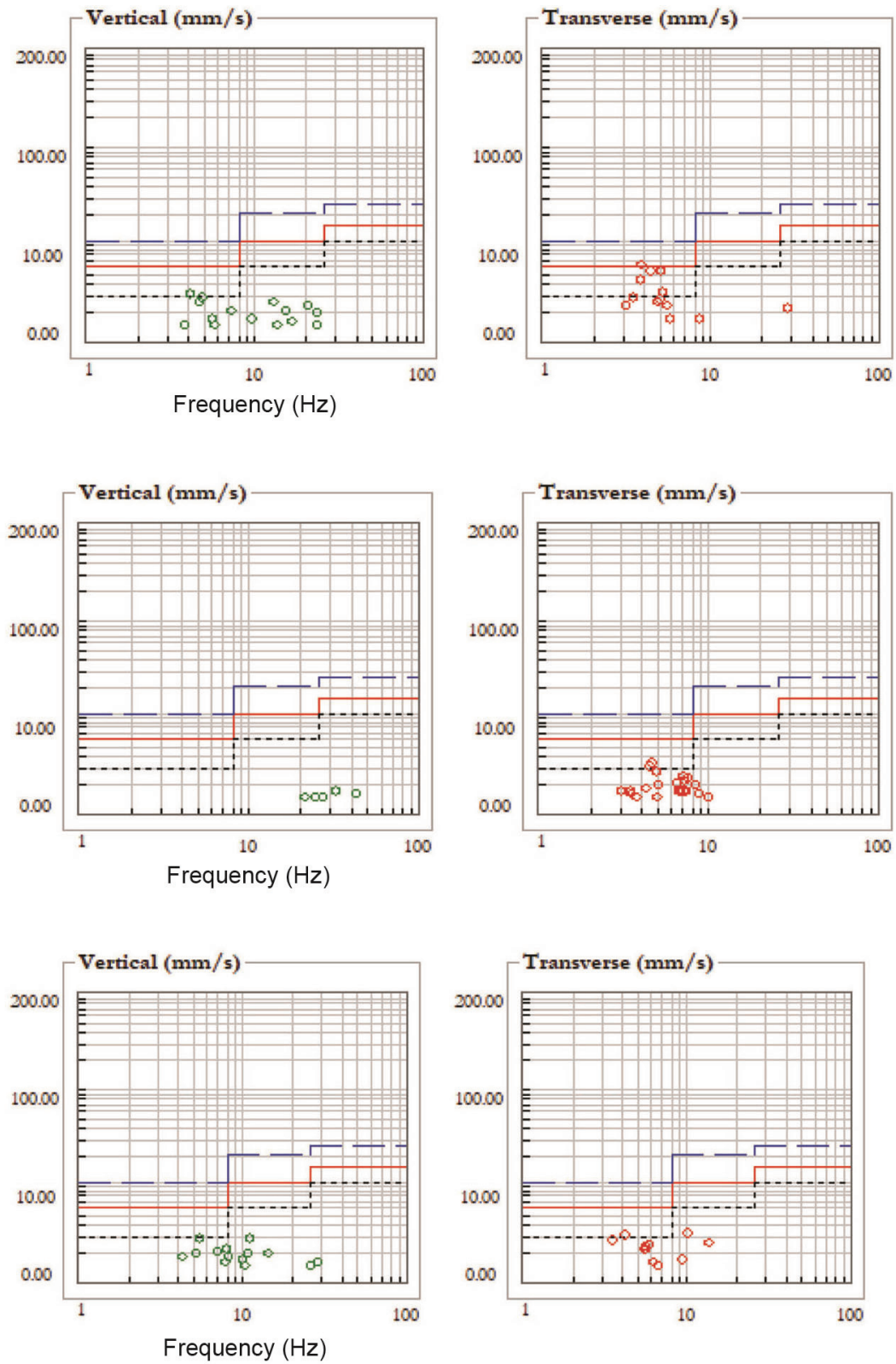
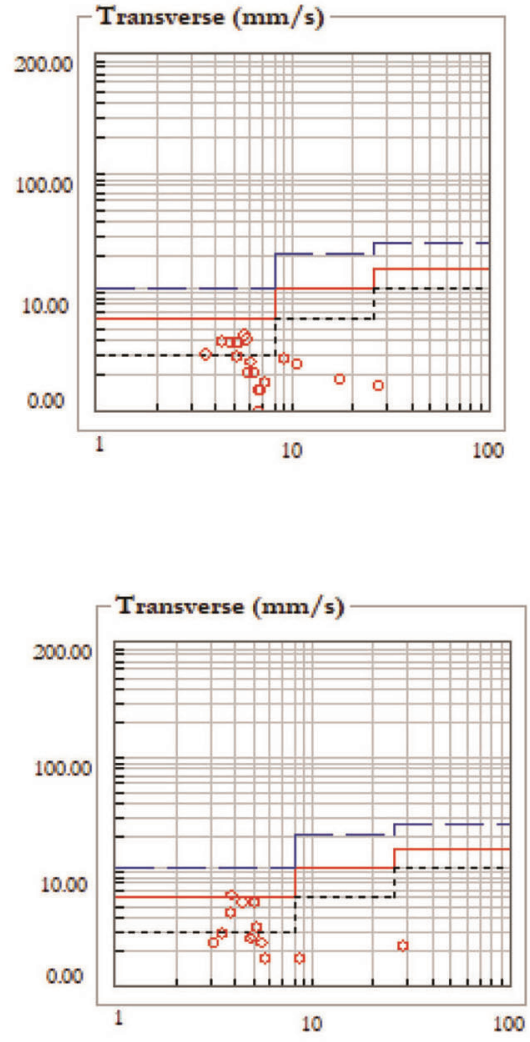


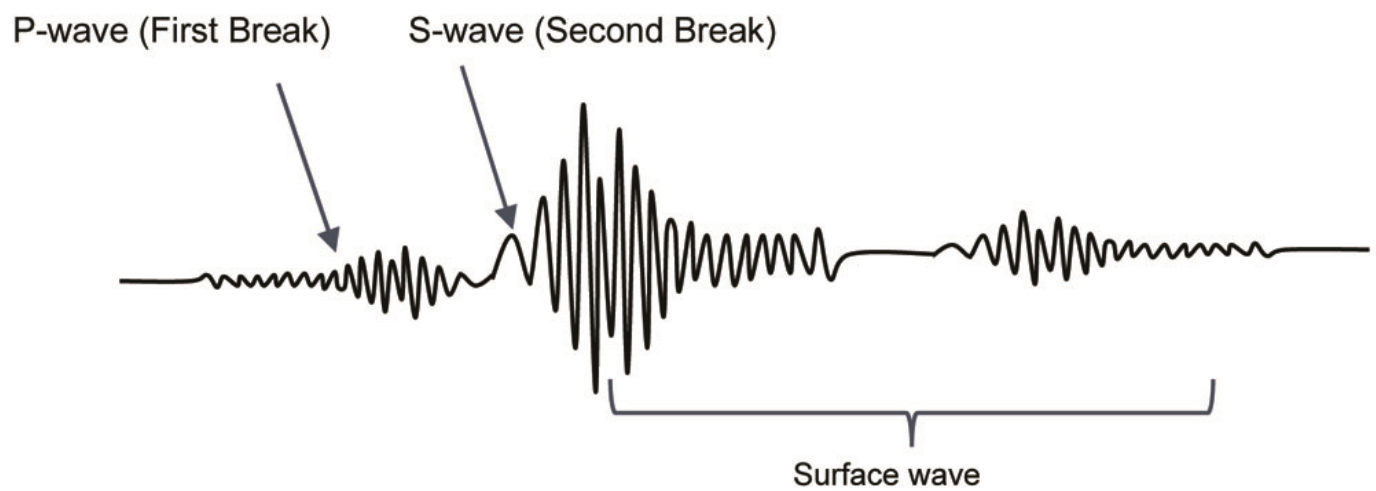

Figure 5. The first, second and third breaks on the given wavelets ${ }^{28}$.

Table 6. Charge weight distribution

\begin{tabular}{lc}
\hline Distance $(\mathrm{m})$ & $\begin{array}{c}\text { Safe charge weight } \\
\text { per delay }(\mathrm{kg})\end{array}$ \\
\hline 200 & 71.74 \\
250 & 112.09 \\
300 & 161.41 \\
350 & 219.69 \\
400 & 286.95 \\
450 & 363.17 \\
500 & 448.36 \\
550 & 542.55 \\
600 & 645.65 \\
650 & 757.74 \\
700 & 878.79 \\
750 & 1008.82 \\
800 & 1147.81 \\
\hline
\end{tabular}

may be used to prevent the damage to structures surrounding opencast mine.

Consideration of permissible limit of peak particle velocity $(5 \mathrm{~mm} / \mathrm{s})$ and observation distance from the blast site enables to derive the expression for the calculation of maximum charge per delay. Table 6 shows the safe distance for a given maximum charge per delay (explosive load) or specific charge. However, the mine management must exercise routine blast vibration monitoring in accordance with the proposed limit of safe charge. The distribution of maximum charge per delay with safe distances is determined by model eq. (5).

$$
\mathrm{PPV}=580.58 *(D / \sqrt{ } Q)^{-1.502} \text {. }
$$

\section{Critical distance assumption}

The distance of monitoring stations and the quantity of explosive charge are essential factors in predicting the BIGV vis-à-vis the safety of structures and people. In the present study, the critical distance is proposed as 300$550 \mathrm{~m}$, from the blast site. The amount of explosive or maximum charge per delay varied from 85 to $475 \mathrm{~kg}$. After the explosion, on measuring the intensity of BIGV at the above distance, the structures were safe on the above given range of explosive. According to the Indian Standard DGMS, domestic structure should be safe within $5 \mathrm{~mm} / \mathrm{s}$ at $<8 \mathrm{~Hz}$. Mostly domestic houses (kuchcha, brickmortar, brick-cement, etc.) are present close to the mine. The peak particle velocity value observed under $300 \mathrm{~m}$ distance from the blast site at the maximum charge per delay was higher. The old and domestic structures were not safe at such level of vibrations generated (Indian Standard (DGMS circular 7 of 1997)). Table 4 shows the standard damage criteria of different structures. A comparison of BIGV velocity and frequency with those of the structure has been made. The interpretation of different structures with amplitude verses frequency logarithmic cross plot have been made as per the provisions of the Indian Standard (DGMS) model (Figure 4). PPV is defined as the maximum value among the component velocities. In Figure 4 , frequency (along $x$-axis) verses component velocities (along $y$-axis) depict the variations of PPV at different distances. Permissible limit and sustainability for the different types of the structures is accessed as: lowest line (lower limit) for the oldest structures; middle line (middle limit) for the domestic structures; and highest line (upper limit) for the industrial structures. According to Figure $4 a$ and $b$, the density of spherical bubbles lies above the lowest line (lower limit) and below the highest line (middle limit) for the peak particle velocity of less than $5 \mathrm{~mm} / \mathrm{s}$ at dominant frequency of less than $10 \mathrm{~Hz}$. This means only the oldest structures would face the damage while domestic and industrial building would be safe. But structures accumulate stress energy. According to Figure $4 c$ and $d$, the peak particle velocity (less than $4.5 \mathrm{~mm} / \mathrm{s}$ ) at dominant frequency (less than $10 \mathrm{~Hz}$ ) depicts that only the oldest structures undergo damage while domestic and industrial building would be safe.

\section{Peak particle velocity assumption}

The radial, transverse and vertical velocity are recorded by seismograph. These velocities are analysed on computer by using super graphic software. It helps in picking the 


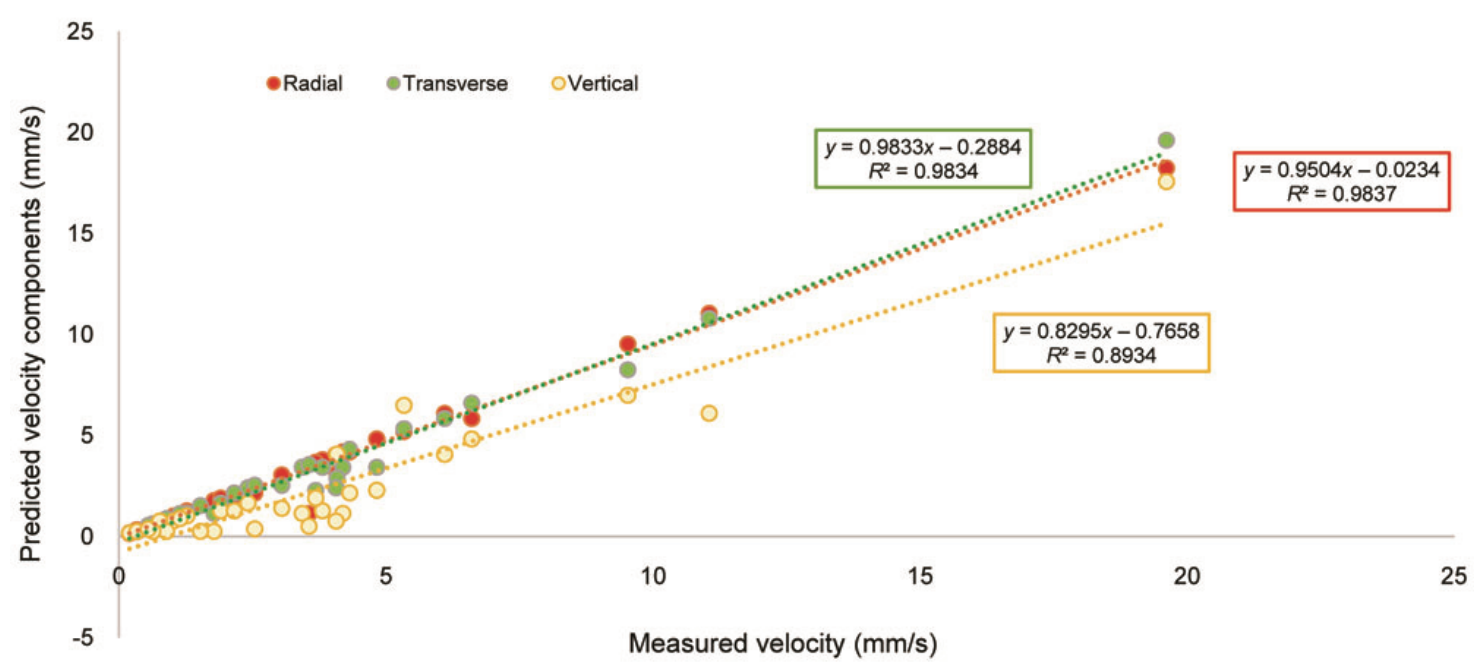

Figure 6. Correlation of component velocities with principal velocity.

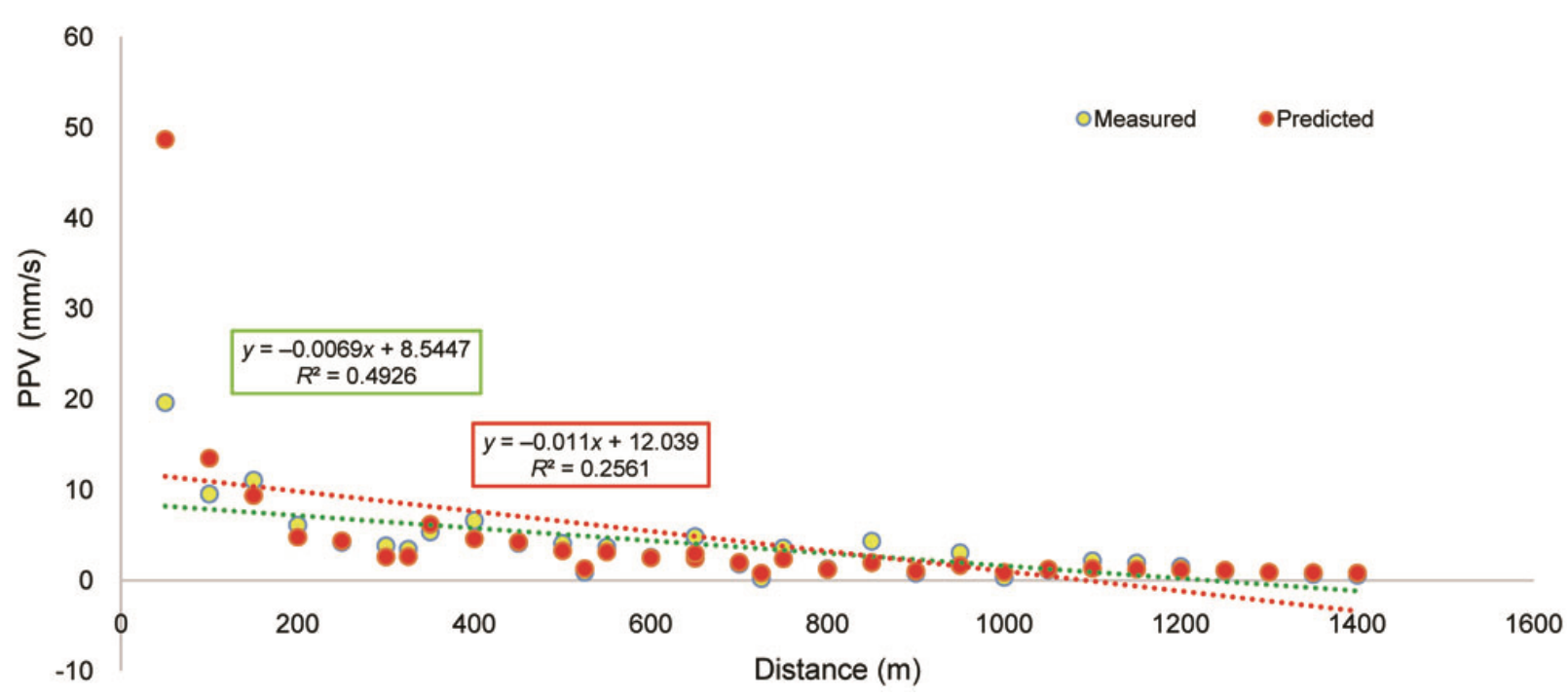

Figure 7. Correlation of measured and predicted PPV with distance.

maximum amplitude among the three velocities to define the peak particle velocity. The first, second and third breaks on the wavelet are defined as the P-wave, S-wave and surface wave respectively. Surface wave has maximum amplitude and causes more damage than the other two waves (Figure 5). PPV is purely a surface wave. By regression analysis correlation between component velocities (radial, transverse and vertical) and PPV has been done. The correlation coefficient of radial, transverse and vertical velocity components are $98.37 \%, 98.34 \%$ and $89.34 \%$ respectively (Figure 6). The radial and transverse velocity components give better correlation with PPV than the vertical component. Further we assume the radial velocity as PPV in the absence of transverse and vertical velocity components, and assume transverse component as PPV in the absence of radial and vertical velocity components.

\section{Correlation}

The correlation coefficient of measured PPV with distance and predicted PPV with distance are $49.26 \%$ and $25.61 \%$ respectively. The correlation between PPV and distance is quantify by these correlation coefficient (Figure 7). This is not good correlation because PPV depends not only on distance but also on the other factor like explosive charge fired in a delay operator. Therefore, the correlation between PPV and scale distance obtained from the correlation coefficient $\left(R^{2}\right)$ of measured and predicted as $63.94 \%$ and $31.28 \%$ respectively (Figure 8 ).

The correlation coefficients for the radial $49.93 \%$, transverse $44.10 \%$, and vertical velocities $35.66 \%$ with observation distance are given in Figure 9. These correlation coefficients were insignificant. The velocity predictor mainly depends on the maximum charge per delay and the 


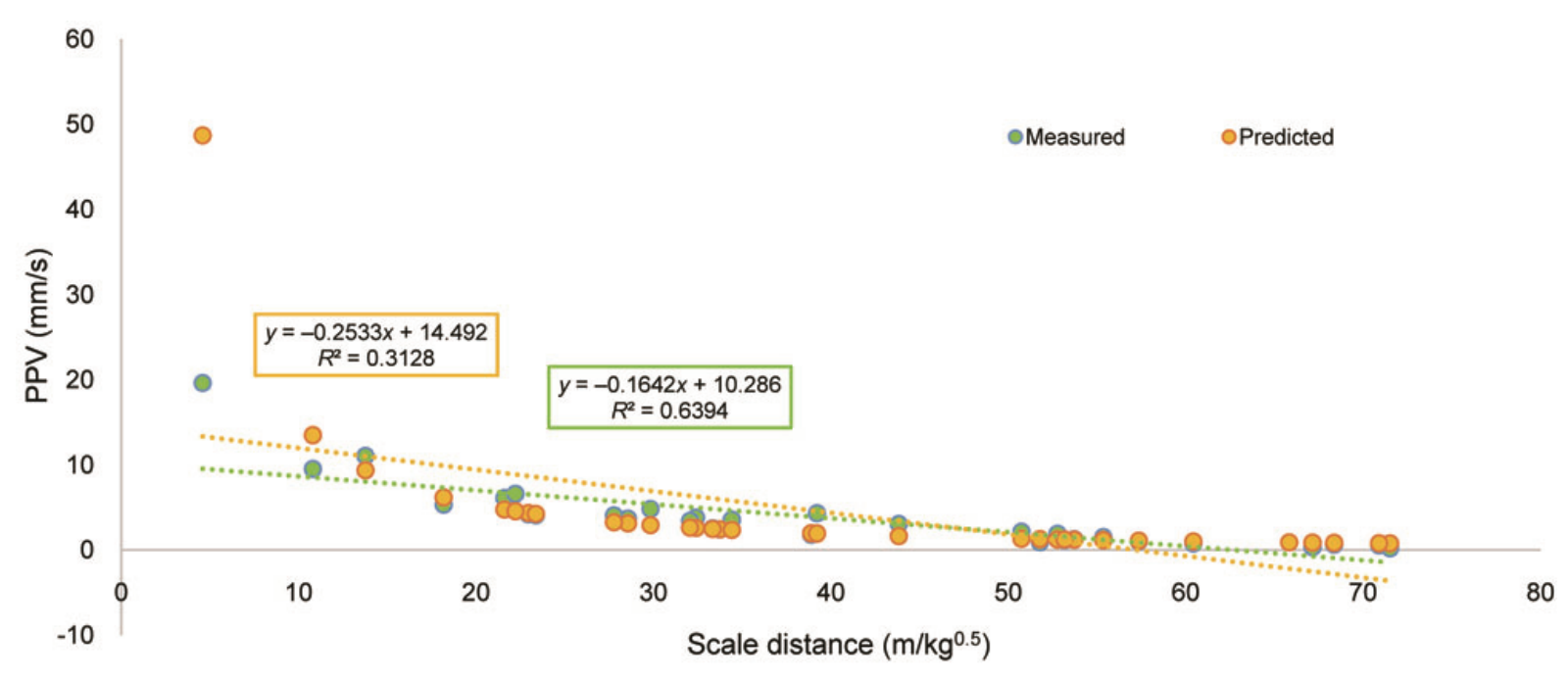

Figure 8. Correlation of measured and predicted PPV with scale distance.

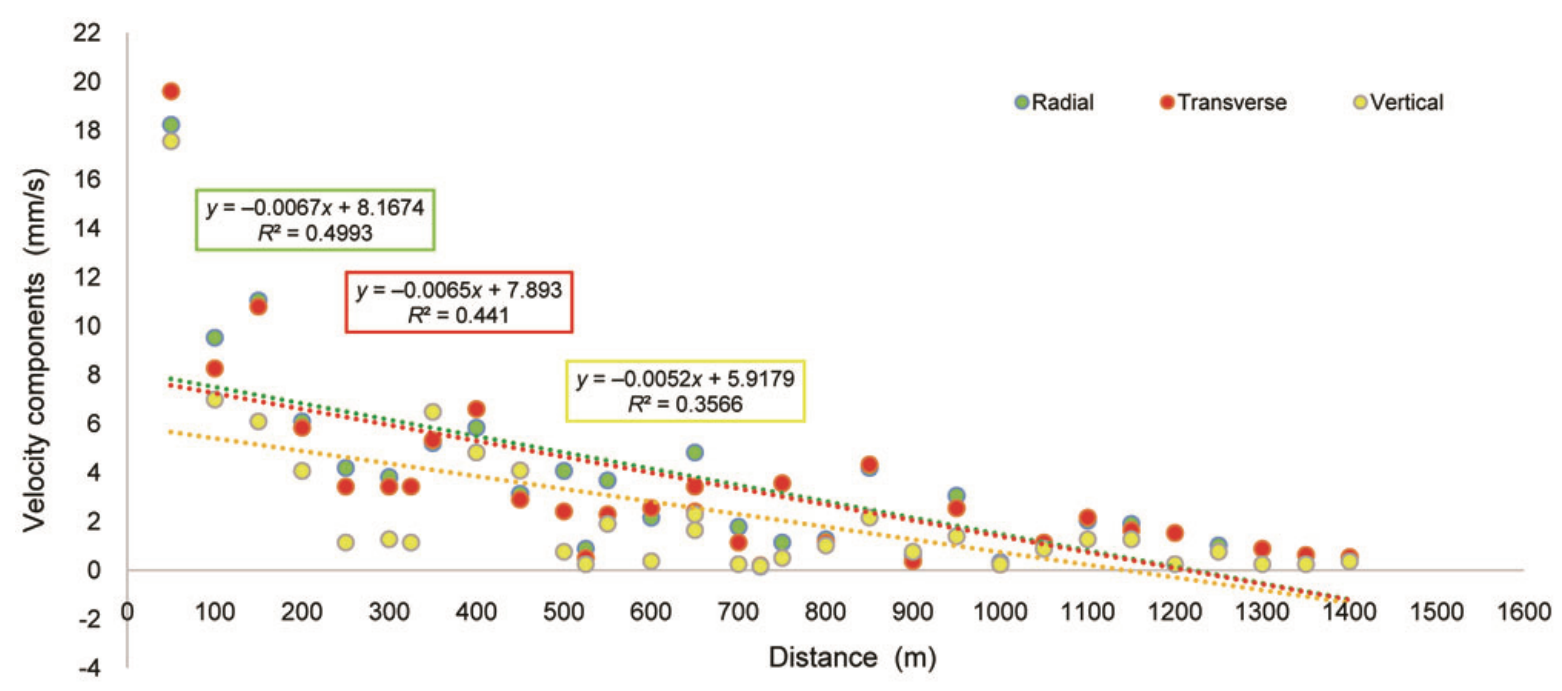

Figure 9. Correlation of velocity components with distance.

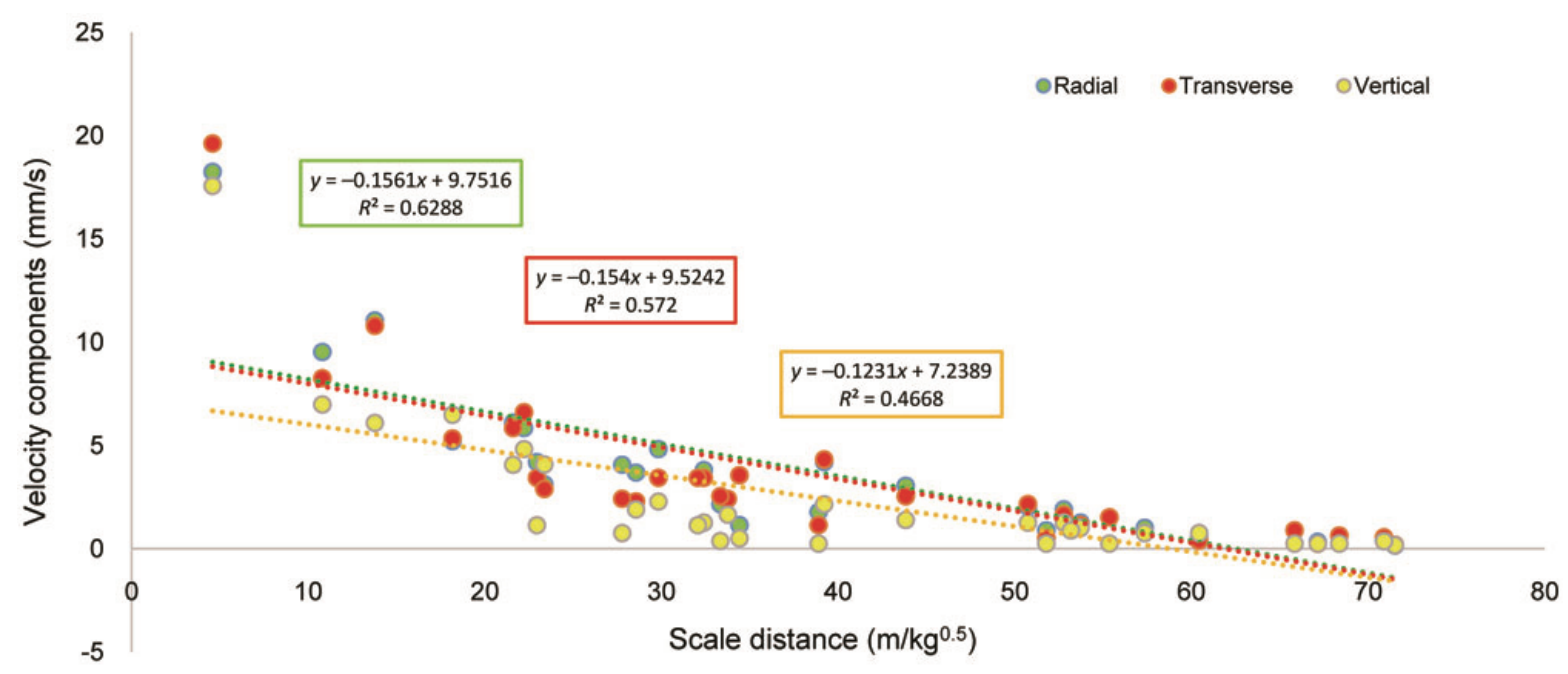

Figure 10. Correlation of velocity components with scale distance. 


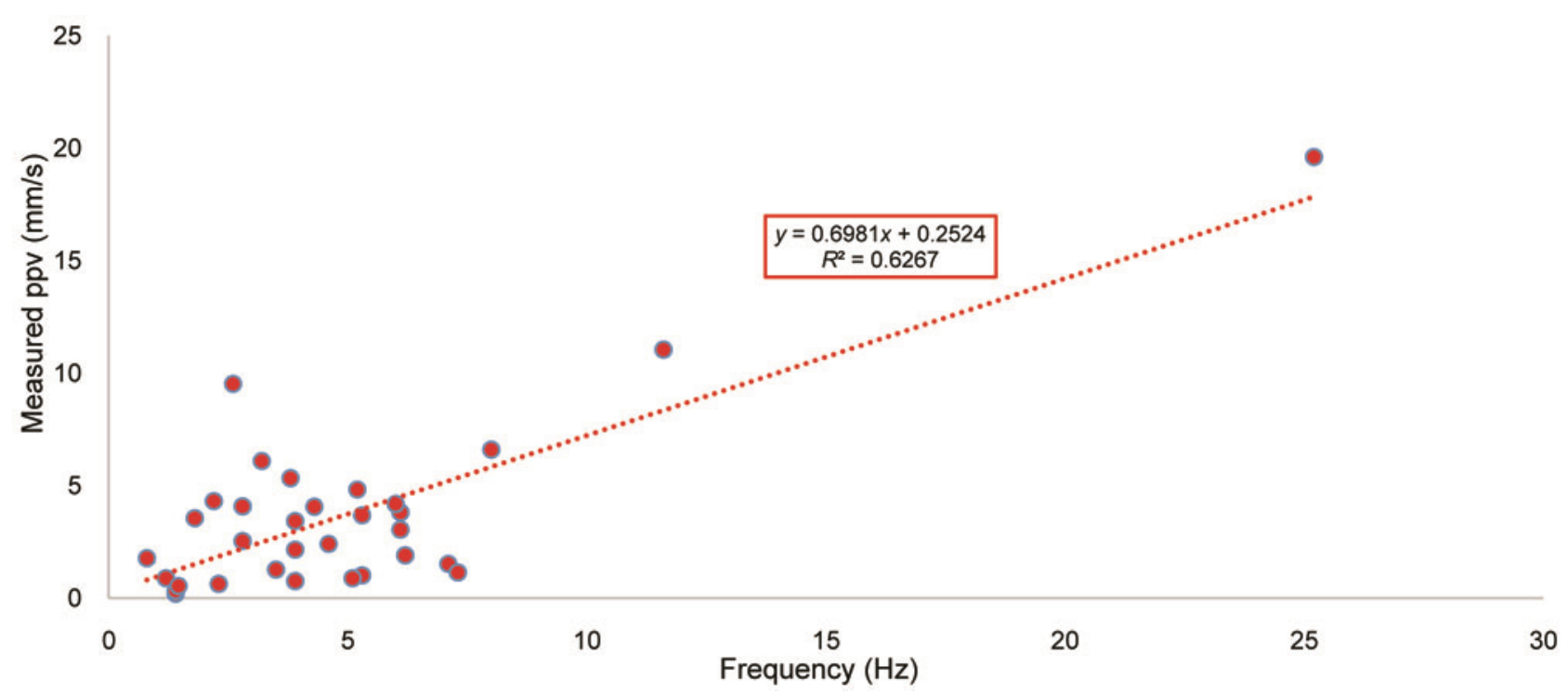

Figure 11. Correlation of measured PPV with measured frequency.

distance while many other factors such as, physical properties of rock mass, geological properties of rock mass, etc. also influence it to some extent. The correlation coefficient of radial is $62.28 \%$, transverse is $75.20 \%$ and vertical velocities is $46.68 \%$ with scale distance shown in Figure 10.

The correlation coefficient between measured PPV and measured frequency was obtained as $62.67 \%$ (Figure 11 ).

\section{Conclusion}

It had been observed that the domestic structures located beyond $550 \mathrm{~m}$ from the blast site with maximum charge per delay $(85-475 \mathrm{~kg})$ would not damage for long period of time. PPV and its components give good correlation with scale distance than the distance. Radial or transverse velocity components are assumed as the principal PPV due to their sufficient correlation coefficient $(98.37 \%$ and 98.34\% respectively). Purely surface wave PPV is more destructive than the body wave. Logarithmic plot amplitude versus frequency establishes a new relationship at every observation point and define the damage criteria of current location structures. This interpretation suggests that there is no serious problem due to blast-induced ground BIGV. The domestic structures only oscillate or vibrate under the suggested peak particle velocity value $(5 \mathrm{~mm} / \mathrm{s})$ at dominant frequency (less than $8 \mathrm{~Hz}$ ) without any damage.

1. Khandelwal, M. and Singh, T. N., Prediction of blast-induced ground vibration using artificial neural network. Int. J. Rock Mech. Min. Sci., 2009, 46(7), 1214-1222.

2. Ak, H., The investigation of directional changes of the blastinduced ground vibration. Doctoral dissertation, Eskisehir Osmangazi University, Turkish, 2006.
3. Arpaz, E., Monitoring and evaluation of blast induced vibrations in some open-pit mines in Turkey. Doctoral dissertation, Cumhuriyet University, Sivas, Turkish, 2000.

4. Re, S. D. and Kopp, J. W., Comparative study of blasting vibrations from Indiana surface coal mine USBM RI 9226, United States, 1989.

5. Dowding, C. H., Blast Vibration Monitoring and Control, Englewood Cliffs, Prentice-Hall, 1985.

6. Pedgen, M., Birch, W. J. and Wetherelt, A., Is that normal? Fundamental observations for best practice blast vibration analysis. In 31 st Annual Conference on Explosives and Blasting Technique, 2005, pp. 221-236.

7. Dowding, C. H., Beck, W. K. and Atmatzidis, D. K., Blast vibration implications of cyclic shear behavior of model plaster panels. Geotech. Test. J., 1980, 3(2), 80-88.

8. Siskind, D. E., Stagg, M. S., Kopp, J. W. and Dowding, C. H., Structure response and damage produced by ground vibrations from surface mine blasting. Report of Investigation RI 8507, US Bureau of Mines Trifunac MD, Brady AG (1975a) on the correlation of seismic intensity scales with the peaks of recorded strong ground motion. Bull. Seismol. Soc. Am., 1980, 65(1), 139-162.

9. Siskind, D. E., Stachura, V. J., Stagg, M. S. and Kopp, J. W., Structure response and damage produced by airblast from surface mining. US Department of the Interior, Bureau of Mines, 1980.

10. Medearis, K., Blasting damage criteria for low rise surface structures. In 4th Annual Conference on Explosives and Blasting Technique, Society of Explosive Engineers, 1978, pp. 280-290.

11. Crandell, F. J., Ground Vibration due to Blasting and its Effect upon Structures, Boston Society of Civil Engineers, Boston, 1949, pp. 222-245.

12. Dowding, C. H., Construction Vibrations, Upper Saddle River, Prentice Hall, NJ, 1996.

13. Medearis, K., The development of rational damage criteria for low-rise structures subjected to blasting vibrations. In The 18th US Symposium on Rock Mechanics (USRMS), American Rock Mechanics Association, OnePetro, US, 1977.

14. Morris, G., Vibrations due to blasting and their effects on building structure. The Engineer, 1950, 190, 394-395.

15. Siskind, D. E., Stagg, M. S., Kopp, J. W. and Dowding, C. H., Structure response produced by ground vibration from surface mine blasting. US Bureau of Mines report RI, US Department of Interior, Bureau of Mines, 1980, vol. 8507. 
RESEARCH ARTICLES

16. Duval, W. I. and Fogelson, D. E., Review of criteria for estimating damage to residences from blasting vibrations. US Bureau of Mines, RI, 1962, 5868 .

17. Nicholls, H. R., Johnson, C. F. and Duvallm, W. I., Blasting Vibrations and their Effects on Structures, US Government Printers, US Department of Interior, Bureau of Mines, 1971, pp. 656660 .

18. Wiss, J. F., Effects of Blasting Vibrations on Buildings and People, Civil Engineering, American Society of Civil Engineers, 1968, vol. 38, pp. 46-48.

19. Singh, P. K., Hennig, A. and Niemann-Delius, C., Vibrations due to blasting in opencast mines, rails and vehicle traffic-some experiences. Int. J. World Min. Surf. Underground, 2005, 57(1), 53-58.

20. Just, G. D. and Chitombo, G. P., The economic and operational implications of blast vibration limit mining and environment. The Aus. IMM, Australia, 1987, pp. 117-124.

21. Singh, P. K. and Roy, M. P., Low frequency vibrations produced by coal mine blasting and their impact on structures. Blast. Fragment., 2008, 2(1), 71-89.

22. Singh, V. K., Northern Coalfields Ltd, surging ahead with time. $J$. Mines Met. Fuels, 2004, 51, 1-52.

23. Regional Director, North Central Chhattisgarh Region, Ground Water Brochure of Korba District, Chhattisgarh, 2012-2013.

24. Deutsches Institut fur Normung (DIN) or German Institute for Standardization, Report on Structural Vibration-Effects of
Vibration on Structures in Deutsche norm, German, 1999, pp. $1-4$.

25. DGMS (tech.) S\&T. Damage of the structures due to blast induced ground vibration in the mine areas; Circular No. 7, 1997, pp. 317322.

26. Parida, A. and Mishra, M. K., Blast vibration analysis by different predictor approaches - a comparison. Proc. Earth Planet. Sci., 2015, 11, 337-345.

27. Kumar, A., Kumar, S., Sharma, S. K. and Singh, C. S., Assessment and prediction of BIGV using different attenuation equation in opencast mine. Int. J. Innov. Technol. Expl. Eng., 2020, 9(4), 2296-2303.

28. Kumar, A., Kumar, S., Sharma, S. K., Kishore, N. and Singh, C. S., Assessment of blast-induced ground vibration frequency in opencast coal mine: a multivariate statistical regression model. Int. J. Innov. Technol. Expl. Eng., 2020, 8(5), 3233-3237.

ACKNOWLEDGEMENT. We thank all mining officers of 'mine A' for providing the necessary facilities during investigations in Chhattisgarh area.

Received 23 September 2020; revised accepted 30 April 2021

doi: $10.18520 / \mathrm{cs} / \mathrm{v} 121 / \mathrm{i} 2 / 275-285$ 